\title{
A experiência da utilização do fluxograma em uma emergência como estratégia de aprendizagem
}

\author{
Cyntia Fiuza Morais, Letícia Rodrigues de Almeida, Luiz Felipe Nobre Queiroz, Mariana de \\ Oliveira Tavares, Ramon Gustavo Barros de Araújo, Kathleen Tereza da Cruz
}

\begin{abstract}
Resumo
Segundo Franco e Mehry, o fluxograma é uma representação gráfica de todas as etapas do processo de trabalho que permite observar e analisar o que acontece em sua operacionalização. Esta ferramenta aplicada numa emergência hospitalar permite avaliar o fluxo dos pacientes, as relações estabelecidas e, a partir disso, os pontos críticos deste processo. Realizado por estudantes no início da graduação, permite um conhecimento realista do fluxo assistencial. Foi relatada a vivência pelos alunos de medicina num Hospital Público, na qual a produção de conhecimento e a vivência no serviço foram os elementos centrais. Foi destacada a importância da inserção precoce na rede, associado à problematização da vivência, tornando-se assim chave para o aprendizado. Compreender o fluxo e os eixos da emergência em um hospital de alta complexidade; evidenciar a importância da vivência prática na formação dos conhecimentos sobre a articulação hospitalar; construir um fluxograma analisador a partir dos dados observados. Foi utilizado o método qualitativo, com observação participante do trabalho dos profissionais e da rotina do pronto atendimento, no primeiro semestre de 2016, às terças-feiras, durante 8 semanas, $8 \mathrm{~h} / \mathrm{semana}$. Como referência analítica, foram utilizados textos técnicos com enfoque em gestão hospitalar, análise de fluxo de pacientes e Acolhimento com Classificação de Risco do Ministério da Saúde, discutidos na disciplina de Saúde da Comunidade II do curso de Medicina. Após esse período de pesquisa, o cerne do estudo se baseou na formulação de um fluxograma analisador. Conforme preconizado pelo Humaniza SUS, um hospital que oferece setor de Urgência e Emergência deve ser dividido em eixos (vermelho e azul), áreas (vermelha, amarela e verde) e planos. Nesse contexto, a montagem do fluxograma evidenciou a distância existente entre os dados literários e a operação prática, sobretudo na relação recíproca entre os eixos. Segundo a bibliografia, os eixos deveriam se comportar de maneira contínua e linear, mas com a vivência foi percebido que suas interações são obstrutivas e sobrepostas. O maior problema da sobreposição dos eixos é a geração de um efeito em cadeia, no qual a obstrução de um deles acaba por afetar os adjacentes. Isso fica nítido quando se observa a interrupção do fluxo na área amarela que congestiona o eixo azul, causando a superlotação da urgência. Esta experiência, a montagem de um fluxograma analisador a partir de saberes práticos, ressaltou a necessidade de um ensino médico mais proativo, saindo da inalterabilidade do conhecimento teórico. Ademais, é importante a inclusão de graduandos desde o início do curso no sistema hospitalar, para fomentação de um conhecimento modelado pela saúde pública brasileira.
\end{abstract}

Descritores: Acolhimento; Emergência; Fluxograma 